\title{
Desain Business Intelligence untuk Manajemen Rumah Sakit
}

\author{
Eka Miranda*, Firmansyah, Davies Ezra Emerald \\ Information Systems Department, School of Information Systems, \\ Bina Nusantara University, Jakarta, Indonesia
}

Naskah Diterima : 7 September 2020; Diterima Publikasi : 27 Mei 2021

DOI: 10.21456/vol11iss1pp62-69

\begin{abstract}
Organizational management, as well as hospital management, could not work precisely without defining the performance indicators to control all business process. This situation encourages the need for information and data analysis availability. BI includes applications, infrastructure, tools and practices that enable organizations to access and analyze data and information to improve and optimize the decisions and organization performance. BI has the potential to improve the quality, efficiency and effectiveness of hospital health services as well. The objective of this study was to design business intelligence prototype for the hospital. BI design was carried out with a Business Intelligence Roadmap approach which has 6 main stages, namely: (1) Justification, (2) Planning, (3) Business Analysis, (4) Design, (5) Construction and (6) Deployment. Data were collected from hospital activities includes registration, Electronic Medical Record (EMR) in the Imaging, Laboratory, Pharmacy, Operating Theater and Medical Check-Up departments activities. Designing BI was preceded by identifying technical and nontechnical needs, then continued by designing BI itself. BI roadmap approach was used for this propose. Technical requirements for designing BI include hardware and software infrastructure readiness, while non-technical requirements include Business Analysis which consists of Project Requirements Definition, Data Analysis, Application Prototyping and Metadata repository Analysis. Designing BI itself includes: Designing a multidimensional database and designing ETL. The user interfaces for BI was shown in the Performance Dashboard, which allows organizations to track all aspects of their daily business activities and performance.
\end{abstract}

Keywords : Business Intelligence; BI roadmap; Hospital; Dashboard

\begin{abstract}
Abstrak
Manajemen organisasi termasuk manajemen rumah sakit tidak dapat bekerja secara tepat tanpa mendefinisikan indikator kinerja untuk mengendalikan seluruh proses bisnis. Hal ini mendorong kebutuhan ketersediaan informasi dan analisis data. Business Intelligence (BI) mencakup aplikasi, infrastruktur, alat, dan praktik yang memungkinkan organisasi mengakses dan menganalisis data dan informasi dengan tujuan untuk meningkatkan dan mengoptimalkan keputusan dan kinerja. BI berpotensi untuk meningkatkan kualitas, efisiensi, dan efektivitas pelayanan kesehatan rumah sakit. Tujuan penelitian ini adalah membuat desain prototipe Business Intelligence untuk rumah sakit. Desain BI dilakukan dengan pendekatan Business Intelligence (BI) Roadmap yang memiliki 6 tahapan utama yaitu : (1) Justificattion, (2) Planning, (3) Business Analysis, (4) Design, (5) Construction dan (6) Deployment. Data penelitian ini yakni data pada kegiatan pelayanan rumah sakit yang meliputi: pendaftaran, Elektronik Medical Record (EMR) pada departemen Imaging, Laboratory, Pharmacy, Operating Theatre dan Medical Check Up. Mendesain BI didahului dengan mengidentifikasikan kebutuhan teknis dan non teknis kemudian dilanjutkan dengan mendesain BI itu sendiri. Untuk keperluan ini digunakan pendekatan BI roadmap. Kebutuhan teknis untuk mendesain BI mencakup kesiapan infrastruktur hardware dan software, sedangkan kebutuhan non teknis meliputi Business Analysis yang terdiri atas Project Requirements Definition, Data Analysis, Application Prototyping dan Metadata Repository Analysis. Mendesain BI itu sendiri meliputi : Mendesain multidimensional database dan mendesain ETL. Antar muka desain BI ditampilkan dalam bentuk Performance Dashboard, yaitu dashboard yang memungkinkan organisasi melacak semua aspek aktivitas harian bisnis dan kinerjanya.
\end{abstract}

Kata kunci : Business Intelligence; Business Intelligence roadmap; Rumah Sakit; Dashboard

\section{Pendahuluan}

Di banyak organisasi, teknologi informasi berperan menangani peningkatan jumlah data yang diproduksi, baik data yang diproduksi dari internal dan eksternal organisasi. Peningkatan jumlah data ini membuat data tersedia untuk dianalis sehingga pengembangan organisasi yang berbasis data merupakan kebutuhan bagi organisasi untuk membantu pengambilan keputusan di semua tingkat (Gaardboea, 2017). Sektor pelayanan kesehatan juga menghasilkan data dalam jumlah besar, hal ini didorong oleh kebutuhan untuk mencatat persyaratan peraturan, dan perawatan pasien (Gaardboea, 2017).

*) Penulis korespondensi: ekamiranda@binus.ac.id 
Manajemen organisasi termasuk manajemen rumah sakit tidak dapat bekerja tanpa mendefinisikan indikator kinerja dengan tepat untuk mengendalikan seluruh proses bisnis. Hal ini mendorong kebutuhan ketersediaan informasi dan analisis data. Penerapan Business Intelligence (BI) untuk rumah sakit membuka kesempatan untuk memenuhi kebutuhan ketersediaan informasi dan analisis data ini. Selain itu pelayanan kesehatan adalah salah satu bidang yang paling digerakkan oleh analisis data dan keputusan yang berbasis data (Escher, 2015).

BI adalah istilah yang mencakup aplikasi, infrastruktur, alat, dan praktik yang memungkinkan organisasi mengakses dan menganalisis informasi dengan tujuan untuk meningkatkan dan mengoptimalkan keputusan dan kinerja (Gartner, 2017). Di bidang medis dan pelayanan kesehatan, sistem BI dirancang untuk menyampaikan informasi pendukung keputusan dan telah berulang kali terbukti memberikan nilai tambah bagi organisasi, selain itu keputusan berdasarkan data menghasilkan informasi yang tepat waktu dan akurat (Kao, 2016).

Penelitian yang dilakukan oleh (Safwan, 2016) mengungkapkan sistem BI dikembangkan untuk mendukung beberapa domain keputusan rumah sakit yaitu: manajemen rumah sakit, audit klinis, pendukung keputusan klinis, dan penelitian klinis.

Di Indonesia sendiri BI mulai dikembangkan untuk rumah sakit seperti digunakan pada manajemen tempat tidur di rawat inap, kepatuhan dokter terhadap pelayanan atau clinical pathway, dan angka kematian (Atsani, 2019)

Penelitian ini bertujuan membuat desain prototipe Business Intelligence untuk diimplementasikan pada rumah sakit dalam hal ini RSU Samarinda Medika Center pada area finance, inventory, length of stay dan bed occupation. Perumusan masalah (research question) untuk mencapai tujuan penelitian ini yaitu: (1) Bagaimana mengidentifikasikan kebutuhan teknis dan non teknis untuk mendesain BI dan (2) Bagaimana mendesain BI untuk rumah sakit. Kontribusi penelitian ini adalah : (1) Identifikasi kebutuhan teknis dan non teknis untuk mendesain BI dan (2) Menghasilkan desain BI untuk rumah sakit.

\section{Kerangka Teori}

\subsection{Business Intelligence}

Business Intelligence (BI) adalah istilah umum yang mencakup aplikasi, infrastruktur dan alat, serta praktik terbaik yang memungkinkan akses dan analisis informasi untuk meningkatkan dan mengoptimalkan keputusan dan kinerja. (Gartner, 2013). BI dapat dipahami dari perspektif teknis dan bisnis. Definisi teknis BI fokus pada aplikasi, infrastruktur, alat, dan penerapan. Dalam konteks ini, sistem BI sering dikategorikan sebagai: (a) Sistem Extract-TransformLoading (ETL) di mana data ditransfer dari sistem transaksi ke data warehouse; (b) Data warehouse
(DW), yang merupakan basis data untuk menyimpan dan menggabungkan data; (c) Alat analitis, seperti Online Analytical Processing (OLAP), yang memungkinkan pengguna untuk mengakses, menganalisis, dan berbagi informasi yang disimpan di DW; dan (d) Lapisan presentasi, yang merupakan antarmuka pengguna (Olszak, 2012). Sedangkan definisi yang mengadopsi perspektif bisnis menekankan BI sebagai konsep dan metode yang bertujuan untuk meningkatkan pengambilan keputusan dalam organisasi (Gaardboea, 2017).

Business Intelligence (BI) merupakan kombinasi dari pengumpulan data, penyimpanan data, dan knowledge management yang digabungkan dengan analytic tools untuk memberikan informasi internal dan kompetitif yang kompleks kepada para perencana dan pembuat keputusan dalam suatu perusahaan. Sistem BI memberikan informasi yang dapat ditindaklanjuti untuk disampaikan dengan waktu, lokasi, dan bentuk yang tepat untuk membantu pembuat keputusan. Hal ini bertujuan untuk meningkatkan ketepatan waktu serta kualitas input untuk proses pengambilan keputusan, sehingga memudahkan pekerjaan manajerial (Loshin, 2012).

Komponen utama dari BI terdiri dari (Patel, 2015):
a. OLAP (Online Analytical Processing)

b. Komponen analisis

c. Manajemen kinerja perusahaan (dalam bentuk Portal, Score-cards, atau Dasboard)

d. Data Warehouse and data marts

e. Sumber data

\subsection{Tipe Business Intelligence}

Tipe Business Intelligence terdiri atas : (1) Strategic Business Intelligence dan (2) Operational Business Intelligence (Boussaid, 2016).

1. Strategic Business Intelligence (Strategic BI)

Strategic BI meningkatkan proses bisnis dengan menganalisis sekumpulan data yang telah ditentukan sebelumnya dan relevan dengan proses bisnis tersebut, serta menyediakan konteks data historis. Selain itu, Startegic BI menyediakan dasar untuk peramalan, penetapan tujuan, perencanaan, dan arahan. Empat parameter penting yang ada pada Strategic BI yaitu : (1) Pengumpulan dan penyimpanan data, (2) Optimasi data untuk analisis, (3) Identifikasi pendorong utama bisnis melalui catatan data masa lalu dan (4) Mencari jawaban atas pertanyaan bisnis utama. Startegic BI menekankan keluarannya pada tampilan grafis seperti bagan dan grafik untuk mewakili tren, peluang, dan bidang masalah.

\section{Operational Business Intelligence (Operational} BI)

Operational BI dikaitkan dengan sumber data transaksional atau operasional dan pelaporan data selama proses bisnis organisasi berjalan. Operational BI memberikan informasi yang sensitif terhadap waktu dan relevan kepada manager operasi, profesional bisnis, dan karyawan lini depan yang 
berhadapan dengan pelanggan untuk mendukung proses kerja sehari-hari. Keluaran dari Operational BI meliputi faktur, jadwal, dokumen pengiriman, penerimaan dan laporan keuangan.

Penelitian ini membuat desain Startegic BI untuk menejemen rumah sakit.

\subsection{Business Intelligence Roadmap}

Business Intelligence roadmap adalah metode yang digunakan untuk mendesain Business Intelligence (Moss, 2003). BI roadmap terdiri atas 6 tahapan utama yaitu : (1) Justificattion, (2) Planning, (3) Business Analysis, (4) Design, (5) Construction dan (6) Deployment. Tahapan lengkap BI roadmap dapat dilihat pada Gambar 1.

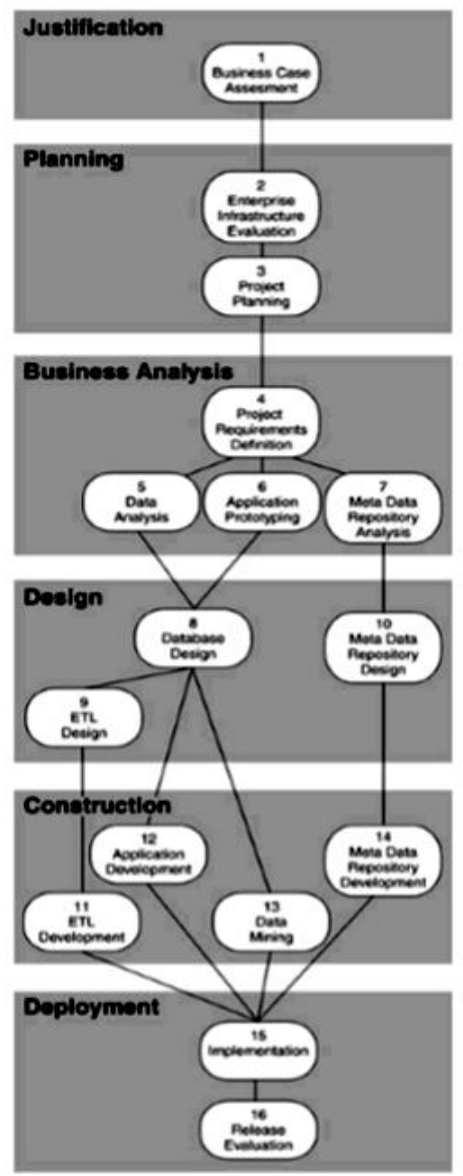

Gambar 1. BI roadmap (Sumber: Moss, 2003)

\subsection{Multidimensional Database}

Multidimensional database adalah jenis database yang dioptimalkan untuk data warehouse dan Online Analytical Processing (OLAP). Multidimensional database dibuat menggunakan input dari database relasional yang ada. Jenis Skema data warehouse terdiri atas : Star schema, Snowflake schema dan Galaxy schema. Star schema adalah pendekatan pemodelan yang diadopsi secara luas oleh data warehouse relasional. Star schema terdiri atas tabel dimensi dan tabel fakta. Tabel dimensi mendeskripsikan entitas bisnis yaitu hal-hal yang akan dimodelkan. Entitas dapat mencakup produk, orang, tempat, dan konsep, termasuk waktu itu sendiri. Tabel dimensi berisi kolom kunci yang berfungsi sebagai pengenal unik, dan kolom deskriptif. Tabel fakta menyimpan observasi atau peristiwa, dan dapat berupa pesanan penjualan, saldo stok, nilai tukar, suhu dan lain lain Tabel fakta berisi kolom kunci dimensi yang berhubungan dengan tabel dimensi, dan kolom ukuran numerik. Kolom kunci dimensi menentukan dimensi tabel fakta, sedangkan nilai kunci dimensi menentukan perincian tabel fakta. (Emany, 2016).

\subsection{Extract, Transform Loading (ETL)}

ETL adalah kependekan dari extract, transform, load, merupakan 3 fungsi database yang digabungkan menjadi satu alat untuk menarik data dari satu database dan menempatkannya ke database lain. Extract adalah proses membaca data dari database. Dalam tahap ini, data dikumpulkan, seringkali dari berbagai jenis sumber. Transform adalah proses mengubah data yang diekstrak dari bentuk sebelumnya menjadi bentuk yang diperlukan agar dapat ditempatkan ke dalam database lain. Transformasi terjadi dengan menggunakan aturan atau tabel pencarian atau dengan menggabungkan data dengan data lain. Load adalah proses penulisan data ke dalam database target (Emany, 2016).

\section{Metode}

\subsection{Data}

Data penelitian ini yakni data pada kegiatan pelayanan rumah sakit RSU Samarinda Medika Citra yang meliputi: pendaftaran, Elektronik Medical Record (EMR) pada departemen Imaging, Laboratory, Pharmacy, Operating Theatre dan Medical Check Up. Rumah sakit saat ini memiliki Sistem Informasi Rumah Sakit. Sistem ini terbagi lagi menjadi 3 subsistem yaitu : (1) ADT (Administration Discharge Transaction), subsistem ini digunakan oleh dokter untuk pencatatan administrasi sebagai sarana menyimpan segala pencatatan yang dimiliki oleh pasien, (2) EMR (Electronic Medical Record), subsistem ini digunakan untuk memasukan data dan melihat laporan medical check up pasien dan penggunanya adalah dokter, serta (3) KiosK, subsistem ini digunakan untuk pendaftaran pasien dan penggunanya adalah bagian administrasi rumah sakit.

\subsection{Tahapan Penelitian}

Tahapan penelitian terdiri atas: (1) Mengumpulkan data, (2) Identifikasi masalah dan (3) Desain BI. Tahapan penelitian ditamilkan pada Gambar 2.

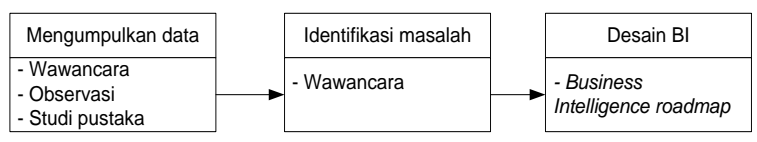

Gambar 2. Tahapan penelitian 


\subsection{Ketersediaan Perangkat Pendukung untuk Mendesain BI}

Berikut merupakan hasil observasi yang diperoleh dari kondisi ketersediaan perangkat pendukung untuk membangun BI yang ditampilkan pada Tabel 1 .

Tabel 1. Ketersedian Perangkat Pendukung untuk Mendesain BI

\begin{tabular}{ll}
\hline & Tersedia \\
\hline Database & $\mathrm{V}$ \\
Data Warehouse & $\mathrm{X}$ \\
Analytical tools (dashboard) & $\mathrm{X}$
\end{tabular}

Rumah sakit sudah memiliki database untuk mengelolal data tapi belum memiliki data warehouse dan analytical tools.

\subsection{Kesiapan rumah sakit dalam mengimplementasikan Business Intelligence}

Untuk membangun BI perlu dilakukan analisa kesiapan perusahaan (rumah sakit) dalam menerapkan BI. Penelitian ini melakukan analisa kesiapan rumah sakit dalam mengimplementasikan BI menggunakan pendekatan BI Rediness Factors. Pendekatan ini digunakan karena dapat menggambar kesiapan perusahaan dalam menerapkan BI dari kesiapan secara teknikal sampai kesiapan berupa dukungan perusahaan. BI readiness factor meliputi (DecisionPath Consulting, 2011) : (1) Penyelarasan strategis (Strategic Alignment), (2) Budaya Perbaikan Proses Berkelanjutan (Continuous Process Improvement Culture), (3) Budaya di Sekitar Penggunaan Informasi dan Aplikasi Analitik (Culture around the Use of Information and Analytical Applications), (4) Manajemen Portofolio BI (BI Portfolio Management), (5) Budaya Rekayasa Proses Keputusan (Decision Process Engineering Culture), (6) Kesiapan Teknis BI dan Data Warehouse (BI and Data Warehouse Technical Readiness) dan (7) Kemitraan Bisnis / TI yang Efektif bagi BI (Effective Business/IT Partnership for BI). Hasil penilaian kesiapan rumah sakit dalam mengimplementasikan BI mengunakan pendekatan BI Readiness Factors ditampilkan dalam Gambar 3.

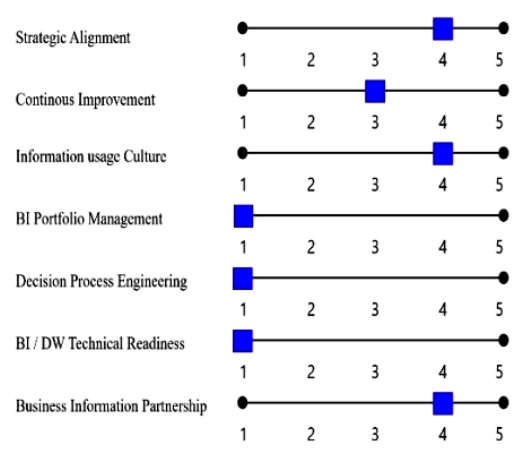

Gambar 3. Kesiapan rumah sakit dalam pengimplementasian BI
Hasil analisis BI readiness factor ditampilkan dalam 5 level untuk mengidentifikasikan kesiapan setiap faktor mendukung implementasi BI. Level 5 menunjukkan level sangat siap dan level 1 menunjukkan level belum siap. Analisis BI Readiness Factors dilakukan melalui wawancara dengan pihak rumah sakit, hasil yang diperoleh menunjukkan bahwa dari faktor BI Portofolio Management, Decision Process Engineering dan BI/ DW Technical Readiness berada pada level belum siap, sedangkan untuk faktor Strategic Alignment, Information Usage Culture dan Business Information Partnership berada pada level siap, dan untuk faktor Continous Improvement berada pada level cukup siap.

\section{Hasil dan Pembahasan}

\subsection{Justification \\ Justification merupakan pengukuran terhadap business requirements sehingga dapat} teridentifikasikan suatu pembangunan proyek yang baru. Business case assessment yang dilakukan terhadap rumah sakit memperoleh hasil bahwa : (1) Rumah sakit memperoleh informasi dari data setiap unit pelayanan rumah sakit. Dalam membantu proses pelayanan pasien mulai dari registrasi sampai pembayaran rumah sakit selama ini menggunakan sebuah sistem informasi rumah sakit. Semua data pelayanan pasien tersebut disimpan didalam sebuah database. Namun, informasi kinerja rumah sakit masih belum dianalisa secara optimal. Saat ini, rumah sakit tidak memiliki aplikasi BI yang dapat digunakan untuk menganalisa jumlah pasien dari setiap unit, Bed Occupation Rate (BOR) serta pendapatan dari keseluruhan unit rumah sakit yang dapat memberikan pengetahuan kepada pihak eksekutif. Selain itu pihak eksekutif rumah sakit juga membutuhkan dashboard yang menyajikan informasi jumlah pasien yang masuk dari setiap unit pelayanan, jumlah bed (tempat tidur) dan pendapatan dari keseluruhan unit pelayanan rumah sakit agar dapat membantu dalam proses mengambil keputusan secara tepat, cepat, dan akurat di saat yang diperlukan, (2) Pihak eksekutif merupakan pengendali dari pengambil keputusan dalam rumah sakit, (3) Kesiapan rumah sakit dalam menerapkan BI telah dibahas pada bagian 3.3 dan dapat dilihat hasilnya pada Gambar 3, (4) Kesiapan perusahaan dari segi hardware dan software juga menjadi salah satu pengukuran kesiapan, (5) Resiko yang mungkin terjadi dalam mendesain BI yaitu : (a) resistensi dari dalam perusahaan untuk berubah, (b) kualitas data, (c) ruang lingkup BI kehilangan momentum dan (d) kekeliruan dalam menempatkan orang untuk tim. Adapun analisa Return on Investment belum dilakukan dalam penelitian ini.

\subsection{Planning}

Pada tahap ini dilakukan evaluasi terhadap infrastruktur yang dimiliki suatu organisasi. Meliputi 
infrastruktur teknis dan non-teknis. Kesiapan infrastuktur teknis rumah sakit ditampilkan pada Tabel 2.

Tabel 2. Kesiapan infrastuktur teknis rumah sakit

\begin{tabular}{lc}
\hline & Tersedia \\
\hline Perangkat keras & $\mathrm{V}$ \\
Prosesor & $\mathrm{V}$ \\
Memori (RAM) & $\mathrm{V}$ \\
Graphic card & $\mathrm{V}$ \\
Hard disk & \\
Perangkat lunak & \\
Sistem operasi & $\mathrm{V}$ \\
Database Management System & $\mathrm{V}$ \\
Middleware & $\mathrm{V}$ \\
\end{tabular}

Evaluasi kesiapan infrastuktur non-teknis dilakukan hanya terhadap kesiapan metadata, karena ketersedian data berperan langsung untuk mendesain BI. Hasil evaluasi kesiapan metadata dapat dilihat pada Tabel 3 .

\subsection{Business Analysis}

\subsubsection{Project Requirements Definition}

Tujuan BI bagi rumah sakit adalah sebagai tools untuk membantu pihak eksekutif dalam memantau kinerja rumah sakit dan pengambilan keputusan. Data yang di tampilkan sangat membantu untuk mempengaruhi pembuatan keputusan dalam hal-hal penting dimana pihak rumah sakit sangat fokus dalam analisa data kinerja rumah sakit.

\subsubsection{Data Analysis}

Data yang digunakan untuk desain BI mencakup data 4 tahun terakhir. Terkait data quality, diketahui bahwa kualitas data sudah baik karena saat ini data sudah disimpan didalam database yang telah memenuhi aturan integrity constraint database yaitu : domain constraint, entity integrity constraint, referential integrity constraint, dan key constraint. Sedangkan terkait data cleansing, data tidak perlu melalui tahap data cleansing karena saat ini data sudah disimpan di dalam database yang telah memenuhi aturan integrity constraint database yaitu : Domain Constraint, Entity Integrity Constraint, Referential Integrity Constraint, dan Key Constraint.

Informasi yang bersifat ad hoc (Pertanyaan dibuat untuk mendapatkan informasi saat diperlukan) terkait dengan keputusan strategis yang mendukung pengambilan keputusan tetapi belum dapat dijawab dengan alat bantu yang tersedia saat ini. Informasi $a d$ hoc tersebut sebagai berikut

a. Tingkat keberhasilan pasien yang ditangani

b. Target pendapatan rumah sakit c. Tingkat keberhasilan tersedianya tempat tidur pasien dalam memenuhi kebutuhan pasien

Jenis query yang dijalankan oleh analis bisnis merupakan query yang sifatnya ad hoc seperti :

a. Seberapa tingkat keberhasilan pasien yang dapat ditangani ?

b. Seberapa target pendapatan rumah sakit ?

c. Seberapa tingkat keberhasilan tersedianya tempat tidur pasien dalam memenuhi kebutuhan pasien ?

\subsubsection{Application Prototyping}

Berikut merupakan hal - hal yang perlu untuk di perhatikan dalam tahap Application Prototyping: (1) Objectives, prototype berupa dashboard BI. Tipe dashboard yang dibuat adalah Performance Dashboard, (2) Scope dan Schedule, dashboard yang dihasilkan menampilkan informasi- informasi yang dibutuhkan untuk setiap unit pelayanan rumah sakit yang meliputi : Department Imaging, Laboratory, Pharmacy, Operating Theatre, Medical Check Up.

\subsubsection{Metadata Repository Analysis}

Metadata dirancang untuk menyimpan informasi kontekstual tentang data bisnis. Metadata sangat penting dalam aplikasi Business Intelligence karena membantu merubah bentuk data ke informasi. Hal yang perlu diperhatikan dalam tahap metadata repository analysis yaitu pihak eksekutif mendapatkan seluruh akses izin untuk metadata, Metadata berisi tabel yang ditampilkan pada Tabel 3 .

Tabel 3. Tabel pada metadata repository

\begin{tabular}{|c|c|}
\hline Tabel & Keterangan \\
\hline Registration & $\begin{array}{l}\text { Tabel ini berisi tentang nomor registrasi } \\
\text { pasien }\end{array}$ \\
\hline DepartmentServiceUnit & $\begin{array}{l}\text { Tabel ini berisi tentang unit- unit } \\
\text { pelayanan yang ada di masing-masing } \\
\text { department rumah sakit }\end{array}$ \\
\hline SiteDepartment & $\begin{array}{l}\text { Tabel ini berisi tentang instalasi } \\
\text { instalasi site yang berada di rumah sakit. }\end{array}$ \\
\hline Department & $\begin{array}{l}\text { Tabel ini berisi tentang department } \\
\text { departmen yang berada di rumah sakit }\end{array}$ \\
\hline ServiceUnit & $\begin{array}{l}\text { Tabel ini berisi tentang unit pelayanan } \\
\text { rumah sakit }\end{array}$ \\
\hline Transaction & Tabel ini berisi tentang informasi \\
\hline ChargesDt & transaksi pasien \\
\hline Item & Tabel ini berisi tentang informasi barang \\
\hline SysGeneralCode & $\begin{array}{l}\text { Tabel ini berisi tentang detail dari kode - } \\
\text { kode transaksi }\end{array}$ \\
\hline JobOrderHd & $\begin{array}{l}\text { Tabel ini berisi tentang informasi header } \\
\text { pesanan. }\end{array}$ \\
\hline Paramedic & Tabel ini berisi tentang informasi dokter \\
\hline Specialty & $\begin{array}{l}\text { Tabel ini berisi tentang informasi } \\
\text { spesialis dokter }\end{array}$ \\
\hline ChartOfAccount & $\begin{array}{l}\text { Tabel ini berisi tentang informasi kode } \\
\text { account }\end{array}$ \\
\hline FiscalPeriodDt & $\begin{array}{l}\text { Tabel ini berisi tentang informasi detail } \\
\text { fiscal period }\end{array}$ \\
\hline AccountPeriod & $\begin{array}{l}\text { Tabel ini berisi tentang informasi } \\
\text { account }\end{array}$ \\
\hline Patient & Tabel ini berisi tentang informasi pasien \\
\hline
\end{tabular}




\subsection{Design}

Tahap desain terdiri atas : (1) Desain database dan

2. Desain ETL.

1. Desain database

Desain model multidimensional database menggunakan 4 langkah : (Kimball, 2008).

a. Memilih proses

Proses yang dianalisa adalah proses pendaftaran, Elektronik Medical Record (EMR) pada departemen Imaging, Laboratory, Pharmacy, Operating Theatre dan Medical Check Up.

b. Memilih grain

Memilih grain yaitu memutuskan apa yang benarbenar ditampilkan didalam table fakta. Grain yang diperoleh adalah TransactionChargesHD, TransactionChargesDt, Registration dan JobOrderHeader

c. Identifikasi dimensi

Pada tahap ini diidentifikasi serta disesuaikan dimensi yang dimiliki oleh setiap tabel fakta. Tabel dimensi dan fakta yang terkait dapat dilihat pada Tabel 4.

Tabel 4. Tabel Fakta dan dimensi

\begin{tabular}{ll}
\hline \multicolumn{1}{c}{ Tabel Fakta } & \multicolumn{1}{c}{ Dimensi } \\
\hline TransactionChargeDT & Waktu, Item, Business \\
& Partner, Service Unit \\
TransactionChargeHD & Waktu, Pasien, Departmen \\
& ServiceUnit \\
Registrasi & Pasien, Service Unit, \\
& Business Partner, waktu \\
JobOrderHD & Waktu, Service Unit, \\
& Paramedic, speciality \\
\hline
\end{tabular}

d. Choosing the fact

Tabel fakta yang digunakan dapat dilihat pada Tabel 4. Star schema dari tabel fakta dan dimensi ditampilkan pada Gambar 4.

Star schema pada Gambar 4 digunakan untuk membuat dashboard bad occupation di mana menampilkan bed occupancy rate yang dapat dianalisa dari dimensi waktu, service unit, business partner dan item.

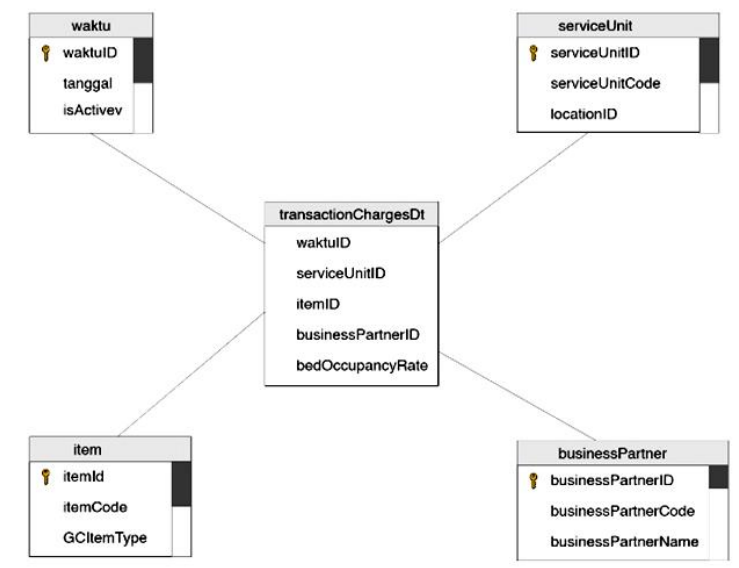

Star schema pada Gambar 5 digunakan untuk membuat dashboard bad occupation di mana menampilkan transaksi pasien rawat inap yang dapat dianalisa dari dimensi waktu, pasien dan department service unit.

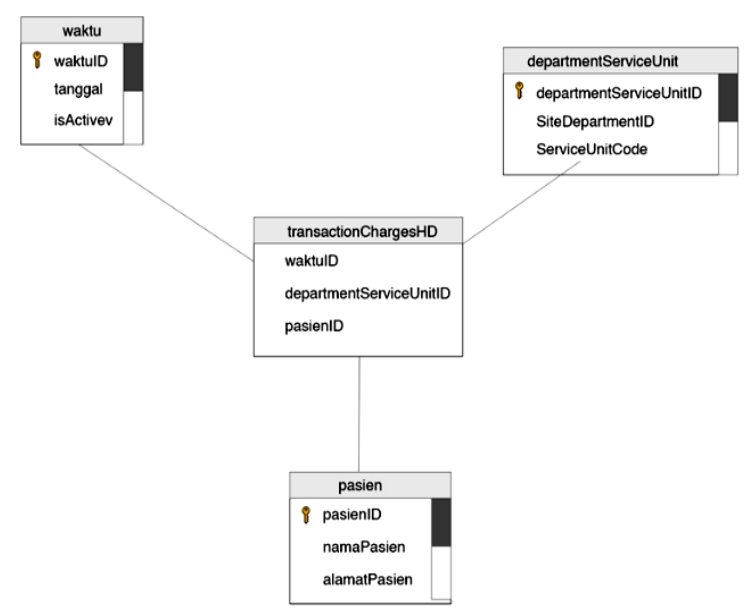

Gambar 5. Star schema TransactionChargedHd

Star schema pada Gambar 6 digunakan untuk membuat dashboard length of stay di mana menampilkan transaksi registrasi rawat inap pasien yang dapat dianalisa dari dimensi waktu, pasien, service unit dan business partner.
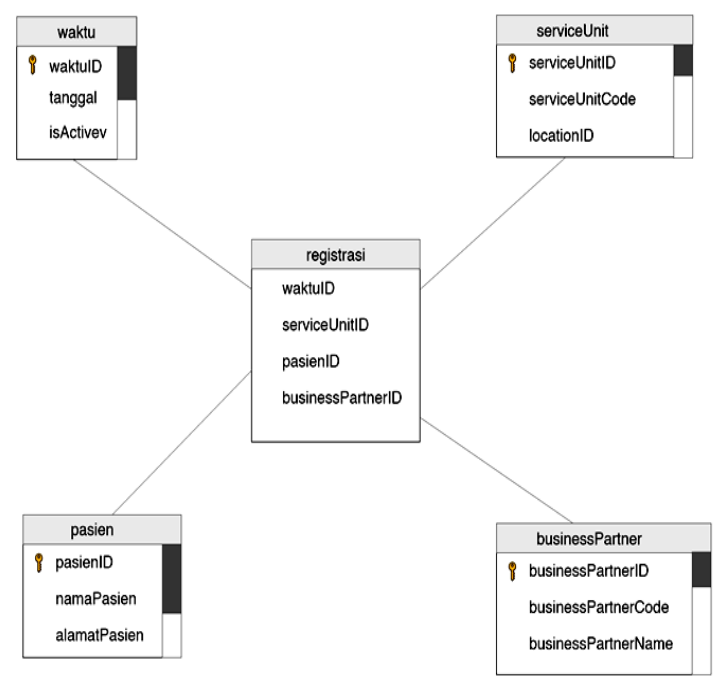

Gambar 6. Star schema Registration

Star schema pada Gambar 7 digunakan untuk membuat dashboard length of stay di mana menampilkan transaksi untuk merawat pasien rawat inap yang dapat dianalisa dari dimensi waktu, service unit, paramedic dan speciality. 


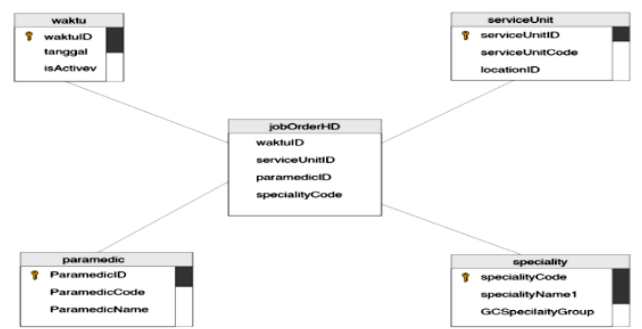

Gambar 7. Star schema JobOrderHd

\section{Desain ETL}

Proses ETL merupakan proses untuk memindahkan data dari database source (OLTP) ke dalam data warehouse (OLAP). Proses ETL yang dilakukan ditampilkan pada Gambar 8.

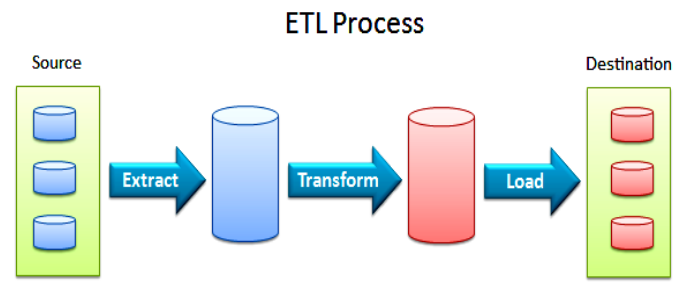

Gambar 8. Proses ETL (sumber: Turban, 2007)

Query dilakukan dengan ekstraksi data dari tabel, yang terdiri atas :

a. Tabel Bed yang menjelaskan prosentase pemakaian tempat tidur pada satu satuan waktu tertentu.

b. Tabel Pasien di kolom LOS (Length of Stay), join dengan tabel Department Service Unit dan Site department menghasilkan penjelasan rata-rata lama perawatan pasien.

c. Tabel Item dan join dengan tabel FiscalPeriodDt serta tabel Department, menghasilkan penjelasan tentang pendapatan rumah sakit dari masingmasing departmen.

d. Tabel Revenue untuk mendapatkan informasi pendapatan keseluruhan rumah sakit.

\subsection{Construction}

Tahap Construction terdiri atas ETL Development dan Application Development. ETL dilakukan menggunakan Microsoft SQL Server 2012. Antar muka desain BI ditampilkan dalam bentuk Performance Dashboard, yaitu dashboard yang memungkinkan organisasi melacak semua aspek aktivitas harian bisnis dan kinerjanya. Visualisasi dashboard Bed Occupation pada Gambar 9 menunjukan tingkat hunian tempat tidur di rumah sakit. Indikator yang ditampilkan adalah bed occupation rate. Indikator ini diperoleh dari kalkulasi jumlah hari perawatan dibagi dengan jumlah tempat tidur tersedia pada periode waktu tertentu. Indikator ini menunjukan persentase pemakaian tempat tidur pada satu satuan periode waktu tertentu. Indikator ini juga memberikan gambaran tinggi rendahnya tingkat pemanfaatan tempat tidur di rumah sakit. Berdasarkan star schema pada Gambar 4 dan 5 indikator Bed Occupation Rate (BOR) dapat dianalisa dari sudut pandang dimensi Waktu, Item, Service Unit dan Pasien.

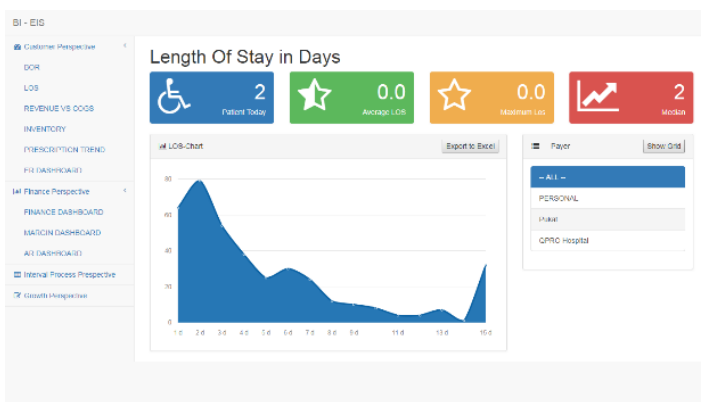

Gambar 9. Bed Occupation dashboard

Visualisasi dashboard Length of Stay pada Gambar 10 menujukan lama perawatan pasien rawat inap. Indikator ini mengacu pada jumlah rata-rata hari rawat inap yang dihabiskan pasien di rumah sakit. Indikator ini diukur dengan membagi jumlah hari tinggal oleh semua pasien rawat inap selama satu tahun dengan jumlah masuk atau keluar pasien. Indikator ini sering digunakan sebagai indikator efisiensi perawatan pasien rawat inap rumah sakit. Indikator ini juga merupakan indikator penting untuk menentukan keberhasilan terapi pasien rawat inap dan juga dapat memberikan gambaran mutu pelayanan rumah sakit. Berdasarkan star schema pada Gambar 6 dan 7 indikator Length of Stay dapat dianalisa dari sudut pandang dimensi Waktu, Item, Service Unit, Paramedic, Speciality dan Pasien.

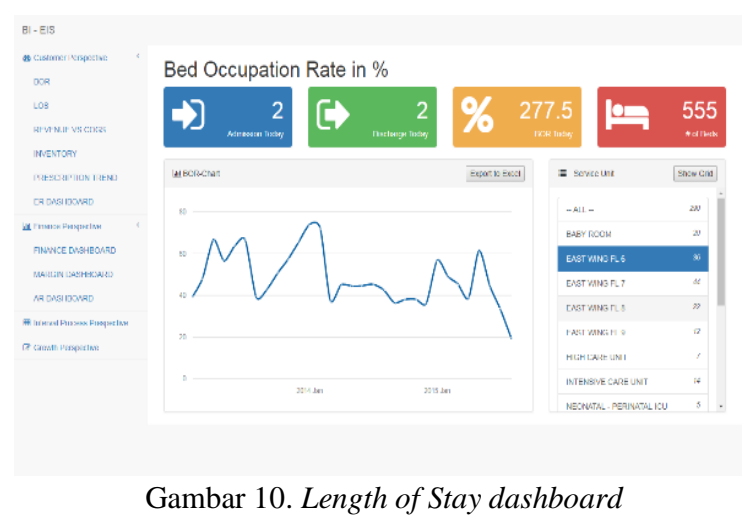

4.6. Deployment

Pada tahap ini mengukur efektivitas penggunaan BI untuk rumah sakit untuk menentukan apakah solusi ini sesuai, melebihi, atau gagal untuk memenuhi harapan organisasi termasuk dari segi investasi yang telah dikeluarkan organisasi. Penelitian belum mengukur efektifitas penggunaan BI termasuk dari segi invertasi. 


\section{Kesimpulan}

Telah dilakukan penelitian mendesain Business Intelligence untuk manajemen rumah sakit. Mendesain BI didahului dengan mengidentifikasikan kebutuhan teknis dan non teknis kemudian dilanjutkan dengan mendesain BI itu sendiri. Untuk keperluan ini digunakan pendekatan BI roadmap. Kebutuhan teknis untuk mendesain BI mencakup kesiapan infrastruktur hardware dan software, sedangkan kebutuhan non teknis meliputi Business Analysis yang terdiri atas Project Requirements Definition, Data Analysis, Application Prototyping dan Metadata Repository Analysis. Mendesain BI itu sendiri meliputi : Mendesain multidimensional database dan mendesain ETL. Konstruksi tampilan antar muka BI ditampilkan dalam bentuk performance dasboard yang membantu eksekutif rumah sakit melacak semua aspek aktivitas harian bisnis dan kinerjanya. Penelitian selanjutnya sebagai penelitian di masa yang akan datang adalah mengukur efektivitas penggunaan BI untuk rumah sakit untuk tentukan apakah solusi ini sesuai, melebihi, atau gagal untuk memenuhi harapan organisasi termasuk dari segi investasi yang telah dikeluarkan organisasi.

\section{Ucapan Terima Kasih}

Ucapan terima kasih kepada RSU Samarinda Medika Citra sebagai narasumber penelitian ini, dan Research and Technology Transfer Office (RTTO), Bina Nusantara University.

\section{Daftar Pustaka}

Atsani, M.R., Anjari, G.A dan N.M, Sarawati, 2019. Pengembangan Business Intelligence di rumah sakit studi kasus: RSUD Prof. Dr. Margono Soekarjo Purwokerto. Telematika, 12(2): 125-138.

Boussaid, O., Bimonte, S. and Schneider, M., 2016. Business intelligence indicators: types, models and implementation. International Journal of Data Warehousing and Mining. 12(4): 75-98.

Decision Path Consulting., 2011, Seven Key Readiness Factors for BI Success. Website: http://www.decisionpath.com/wpcontent/uploads/2011/04/Seven-Key-ReadinessFactors-3.0.pdf, diakses 1 September 2020.
Escher, A., Hainc, N. and Boll, D., 2015. Business intelligence in hospital management. Health Management., 5(4), 1-4.

Gaardboea, R., TNyvanga, T. and Sandalgaardb, N., 2017. Business intelligence success applied to healthcare information systems, Procedia Computer Science 121(8), Barcelona, 483-490.

Gartner Inc, 2017. Business Intelligence (BI). Website:http://www.gartner.com/itglossary/business-intelligence-bi/

Kao, H,Y., Yu, M.C., Masud, M., Wua, W.H., Chen, L.J. and Jim, W.Y.C., 2016. Design and Evaluation of Hospital-Based Business Intelligence System (HBIS): A foundation for Design Science Research Methodology. Computers in Human Behavior. 62: 495-505.

Kimball, R., 2008. The Data Warehouse Lifecycle Toolkit. Wiley. New Jersey.

Loshin, D., 2012.. Business Intelligence. The Savvy Manager's Guide. Morgan Kaufmann, Boston.

Moss, L.T. and Atre, S., 2003. Business Intelligence Roadmap: The Complete Project Lifecycle for Decision-Support Applications, First Edition, Addison-Wesly, Boston, MA.

Olszak, C.M. and Ziemba, E., 2012. Critical success factors for implementing business intelligence systems in small and medium enterprises on the example of upper silesia, Poland. Interdisciplinary Journal of Information, Knowledge, and Management ( 7): 129-150.

Patel, K., Gupta, R., Punde, A., Pillay, A. and M.Vyas., 2015. Study of approaches and components of business intelligence. International Journal Of Engineering Sciences \& Research Technology, 4(2):19-22.

Safwan, E.R., Meredith, R. and Burstein, F., 2016. Business intelligence (BI) system evolution: a case in a healthcare institution. Journal of Decision Systems, 25(S1): 463-475.

Sidi, E., Merouani, M.E., Abdelouarit, E.M.A., 2016. Star schema advantages on data warehouse: using bitmap index and partitioned fact tables. International Journal of Computer Applications 134(13), 11-13.

Turban, E. and Aronson, J.E., 2007. Decision Support Systems and Intelligent Systems, Seventh Edition, Prantice Hall, New Jersey. 